
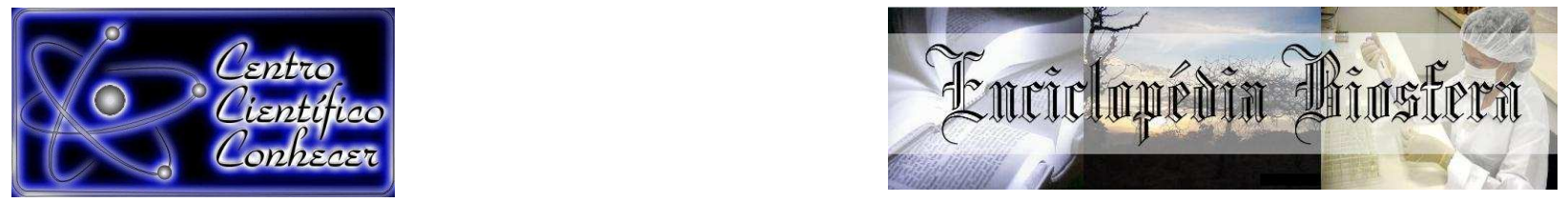

\title{
CARACTERIZAÇÃO DA PESCA ARTESANAL EM MUNÍCIPIOS DA BAIXADA MARANHENSE - BRASIL
}

\footnotetext{
Arlene dos Santos da Silva ${ }^{1}$, Lygia Silva Galeno ${ }^{2}$, Luciana da Silva Bastos ${ }^{3}$, Felício Garino Júnior ${ }^{4}$, Francisca Neide Costa ${ }^{5^{*}}$

${ }^{1}$ Mestre em Ciência Animal pela Universidade Estadual do Maranhão - UEMA, Campus Paulo VI, MA - Brasil.

${ }^{2}$ Graduanda em Medicina Veterinária pela Universidade Estadual do Maranhão UEMA, MA - Brasil.

${ }^{3}$ Mestranda em Saúde e Ambiente pela Universidade Federal do Maranhão - UFMA, MA - Brasil.

${ }^{4}$ Professor Doutor da Universidade Federal de Campina Grande, PB - Brasil.

${ }^{5}$ Professora Doutora da Universidade Estadual do Maranhão - UEMA. Centro de Ciências Agrárias. Departamento de Patologia. Cidade Universitária Paulo VI - Caixa

Postal 09, MA - Brasil. E-mail: francisca.cca.uema@gmail.com (autora correspondente)
}

Recebido em: 08/04/2016 - Aprovado em: 30/05/2016 - Publicado em: 20/06/2016 DOI: 10.18677/Enciclopedia_Biosfera_2016_023

\begin{abstract}
RESUMO
O presente estudo teve como objetivo caracterizar a pesca artesanal em três municípios da Baixada Maranhense, buscando contribuir com as pesquisas da cadeia produtiva da pesca extrativa na região. Foram realizadas observações in situ e aplicação de questionários semiestruturados buscando caracterizar as condições nos locais de comercialização do peixe. De acordo com os resultados encontrados, constatou-se que a comercialização ocorre em feiras livres, com exceção do município de Matinha, onde a mesma é realizada em mercado municipal. Ainda assim, nenhum dos locais apresenta infraestrutura física e higiênica em conformidade com os padrões estabelecidos pela legislação, embora, as piores condições tenham sido observadas nas feiras. Dos 45 pontos avaliados, apenas $28,9 \%$ utilizavam caixa térmica com gelo para refrigeração. A pesca artesanal é realizada como forma de subsistência pelas famílias desses municípios: $90,9 \%$ dos entrevistados em São Bento, 87,5\% em Pinheiro e 90\% em Matinha. Esses resultados demonstram a necessidade de medidas educativas com os recursos humanos envolvidos na cadeia produtiva da pesca artesanal para possibilitar uma melhor remuneração com a atividade.
\end{abstract}

PALAVRAS-CHAVE: feira livre, pescado, saúde pública

\section{CHARACTERIZATION OF THE ARTISANAL FISHERIES IN MUNICIPALITIES OF BAIXADA MARANHENSE - BRAZIL}

ABSTRACT

This study aimed to characterize artisanal fisheries in three municipalities of Baixada Maranhense, seeking to contribute to the research of the productive chain of the 
extractive fishing in the region. We performed in situ observations and application of semi-structured questionnaires seeking to characterize the conditions in fish commercialization venues. According to results we found that sales occur in street markets, excepting Matinha, where sales occur in the municipal market. Even so, no local presents physical and hygienic infrastructure according to Brazilian law, though, the worst conditions were observed at street markets. 45 commercial establishments were observed and just in $28.9 \%$ they have used boxes with ice to preserve fish. Artisanal fishing as a means of livelihood for families of these municipalities is still a reality: $90.9 \%$ of respondents in São Bento, $87.5 \%$ in Pinheiro and $90 \%$ in Matinha, These results show that educational measures with the human resources involved in the production chain of artisanal fisheries are necessary for better remuneration.

KEYWORDS: street market, fish, public health

\section{INTRODUÇÃO}

A pesca artesanal no Brasil apresenta importância social, tanto no contexto local, como regional, sendo fonte de subsistência de populações ribeirinhas que dependem desta atividade diretamente ou indiretamente através de atividades relacionadas (SANTOS et al., 2012). Além disso, esta atividade tem uma contribuição significativa no âmbito socioeconômico para muitas comunidades, pois, serve como fonte de alimento, trabalho e fortalecimento cultural (MARUYAMA et al., 2009).

O peixe é considerado um alimento saudável à dieta humana, sendo fonte de proteína animal de alto valor biológico e de vários nutrientes que proporcionam efeitos benéficos à saúde. Em função deste alto valor nutricional o consumo de peixe no Brasil aumentou significativamente, principalmente, devido às mudanças nos hábitos alimentares da população, porém o consumo é fortemente dependente de fatores ligados aos hábitos alimentares e aos aspectos econômicos que envolvem a oferta e demanda em cada região de produção (FAO, 2012).

Estudos têm demonstrado que a população brasileira já consome peixe acima da média recomendada pela Organização Mundial da Saúde (OMS), que é de 12 quilos por habitante/ano. Em 2013 o consumo médio por habitante/ano foi de 14,5kg (BRASIL, 2014).

$\mathrm{Na}$ região Nordeste, assim como na Baixada Maranhense, a comercialização do peixe acontece, principalmente, em feiras livres e mercados municipais. A feira livre é considerada um dos locais mais tradicionais de comercialização de alimentos a varejo, sendo uma forma de comércio móvel, com circulação dentro dos espaços urbanizados. Esses locais se destacam pela comercialização de alimentos in natura, grande variedade de produtos e pela diversidade de preços, trazendo assim comodidade aos consumidores (GOMES et al., 2012).

Contudo, as feiras livres podem ser apontadas como locais que apresentam condições inadequadas para a comercialização de produtos de origem animal, onde os alimentos ficam expostos em condições precárias de higiene, sem refrigeração e sem proteção contra poeira e insetos (BARRETO et al., 2012), propiciando condições para a sua contaminação e, consequentemente deterioração e aumento de risco de ocorrência de Doenças Transmitidas por Alimentos (DTAs).

O peixe, por ser um alimento altamente perecível necessita de condições adequadas de armazenamento e comercialização, para garantir uma boa qualidade e segurança alimentar. Tendo em vista a importância social e econômica do peixe 
de água doce para a microrregião da Baixada Maranhense, o presente estudo objetivou caracterizar as condições dos locais de comercialização em três municípios da Baixada Maranhense, buscando contribuir com as pesquisas da cadeia produtiva da pesca extrativa na região.

\section{Área de estudo}

\section{MATERIAL E MÉTODOS}

A microrregião da Baixada Maranhense (159'- 400S e 4421'-4533'W), pertence à mesorregião do Norte Maranhense e está localizada a oeste do estado do Maranhão. A região está dividida em 21 municípios e possui uma área de 17.579, $366 \mathrm{~km}^{2} \mathrm{com}$ uma população estimada em 563.877 habitantes (IBGE, 2010). Foram selecionados para estudo os municípios de São Bento, Pinheiro e Matinha por apresentarem a pesca artesanal como principal atividade de sustento e geração de emprego (Figura 1).

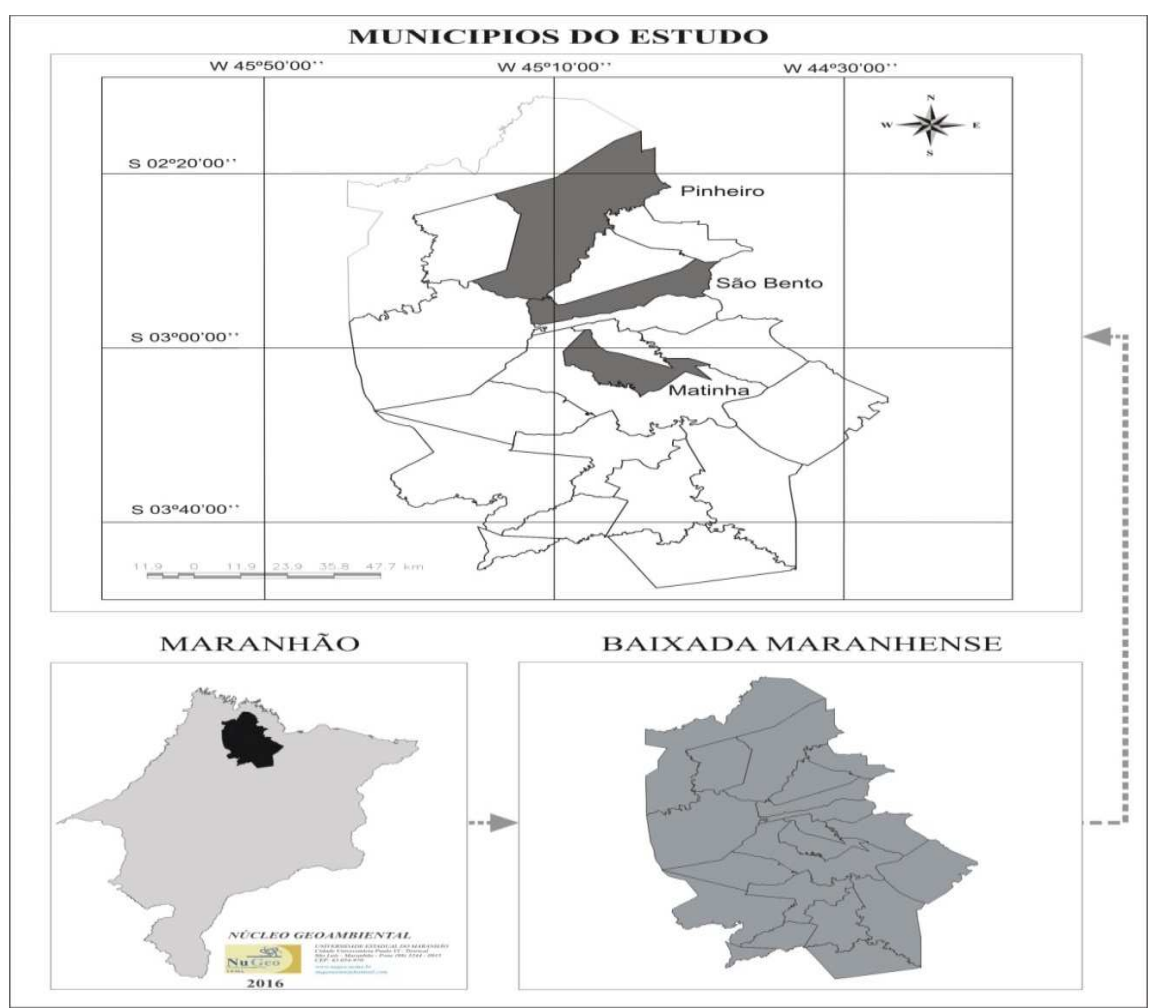

FIGURA 1 - Localização dos municípios estudados na Baixada Maranhense, Brasil. Fonte: NUGEO, 2016.

\section{Amostragem}

Foi realizada uma pesquisa exploratória com análise qualitativa e investigativa, por meio do preenchimento de questionários semiestruturados e observações in situ, no período de fevereiro a outubro de 2015, sendo realizado o levantamento das condições higienicossanitárias dos locais que comercializam peixes nos municípios estudados.

A população selecionada para este estudo era constituída de pescadores, vendedores e manipuladores envolvidos na cadeia produtiva da pesca artesanal. Os 
mesmos foram abordados no mercado e feiras onde ocorria a comercialização do peixe. $\mathrm{Na}$ ocasião, foram prestados esclarecimentos sobre a pesquisa, solicitada autorização formal de participação, por meio do Termo de Consentimento Livre e Esclarecido e só responderam ao questionário aqueles que, após a explicação, assinaram o referido documento.

Foram aplicados dez questionários no município de Matinha, 24 no município de Pinheiro e 11 em São Bento, totalizando 45, os quais buscavam obter informações sobre os aspectos dos pontos em que ocorria a comercialização, assim como qual o destino dos resíduos do peixe destes municípios.

\section{Análise Estatística}

Todos os dados foram digitalizados em planilhas eletrônicas do Microsoft Excel versão 2010 e, posteriormente, submetidos à análise estatística descritiva e os resultados foram expressos em porcentagens e apresentados em tabela.

\section{RESULTADOS E DISCUSSÃO}

A segurança alimentar abrange vários fatores e etapas, sendo a comercialização um ponto importante dentro dessa cadeia. No que se refere à cadeia produtiva da pesca artesanal, a etapa de venda apresenta-se de forma relevante, pois, o peixe é altamente perecível.

No presente trabalho, constatou-se que nos municípios de Pinheiro e São Bento a comercialização ocorre em feiras livres, e em Matinha, em mercado municipal. Ainda assim, nenhum dos locais apresenta infraestrutura física e higiênica em conformidade com os padrões estabelecidos pela legislação (BRASIL, 2002) embora, as piores condições tenham sido observadas nas feiras.

Quanto ao método de armazenamento e conservação do produto, foi observado que na maioria dos pontos, não se empregava gelo para manter o peixe fresco resfriado, como preconiza a legislação, $54,6 \%$ dos pontos avaliados no município de São Bento, e 45,8\% dos pontos avaliados no município de Pinheiro não utilizavam caixa térmica durante a comercialização. Nesses locais, o peixe era armazenado em recipientes de palha ou exposto em bancadas de madeira à temperatura ambiente. Já no munícipio de Matinha, 80\% dos pontos avaliados utilizavam caixa térmica sem gelo. Em ambas as situações o alimento encontrava-se sem proteção e resfriamento, situação que pode ocasionar riscos à população devido à alta perecibilidade dessa proteína animal (Figura 2). 


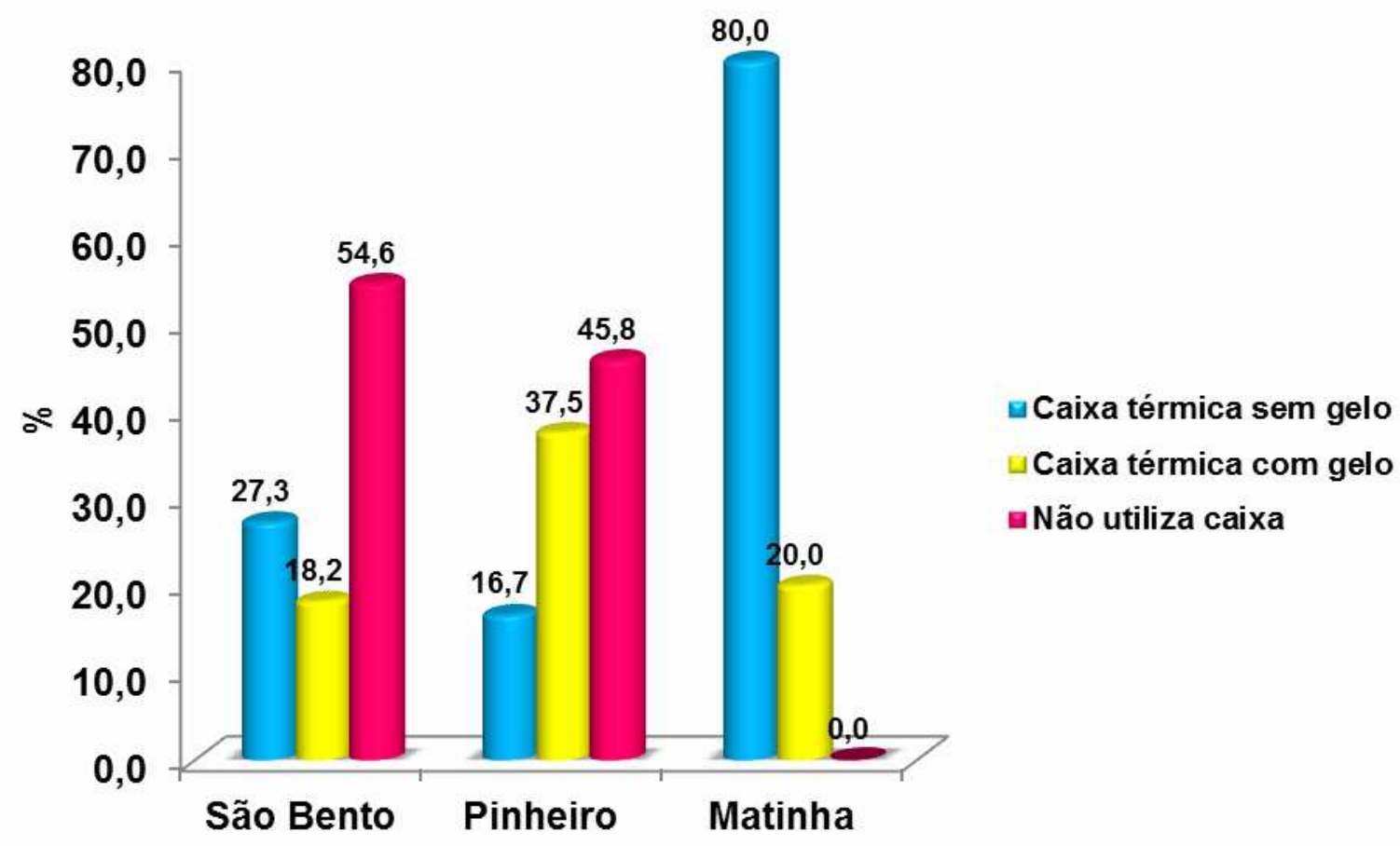

MUNICÍPIOS

FIGURA 2 - Forma de armazenamento do peixe comercializado em três municípios da Baixada Maranhense, Brasil

Fonte: dados da pesquisa

Ressalta-se que o controle da temperatura durante a comercialização é de suma importância para garantir a qualidade e conservação do peixe que possui características favoráveis ao desenvolvimento de micro-organismos deteriorantes e patogênicos. Assim, é imprescindível conservar o peixe em temperaturas baixas, sobretudo em regiões tropicais, onde durante o verão as temperaturas são elevadas, exigindo um controle rigoroso para que suas propriedades organolépticas e nutricionais sejam mantidas, além da segurança alimentar.

Segundo OETTERER (2001), para a venda desse alimento in natura, é essencial que este esteja em estado de frescor. Para tanto, a conservação deve ser iniciada logo após o mesmo sair da água, com gelo em escamas, intercalando-se com camadas de peixe, situação que não foi verificada em nenhum dos locais estudados. Mesmo nos pontos comerciais dos três municípios que utilizam o gelo para resfriamento $(28,9 \%)$, o mesmo é utilizado em barras e colocada apenas uma camada sob o peixe.

Ao estudar as condições da comercialização do pescado em supermercados no estado da Bahia, BARRETO et al. (2012) constataram que a deficiência na conservação desse produto ocorre porque é comum desligarem as ilhas de congelamento durante a noite almejando a economia de energia elétrica, embora essa medida comprometa a qualidade do pescado.

Em relação à forma de comercialização, dos 45 entrevistados neste estudo, $31,1 \%$ responderam que vendem o peixe eviscerado. A preferência do consumidor em adquirir nesses locais esse alimento sem as vísceras ocorre devido à praticidade, um achado preocupante, haja vista, que nos três municípios a água utilizada para fazer a lavagem pós-evisceração era armazenada em recipientes ENCICLOPÉDIA BIOSFERA, Centro Científico Conhecer - Goiânia, v.13 n.23; p. 256 2016 
apresentando sujidades, podendo contribuir para contaminação por microorganismos, aumentando os riscos da veiculação dos agentes patogênicos aos consumidores (Tabela 1).

TABELA 1 - Características dos locais de comercialização de peixe em três municípios da Baixada Maranhense, Brasil.

\begin{tabular}{|c|c|c|c|c|c|c|c|c|}
\hline \multirow{2}{*}{$\begin{array}{l}\text { Características dos locais } \\
\text { de comercialização }\end{array}$} & \multicolumn{2}{|c|}{ São Bento } & \multicolumn{2}{|c|}{ Pinheiro } & \multicolumn{2}{|c|}{ Matinha } & \multirow[b]{2}{*}{ Total } & \multirow[b]{2}{*}{$\%$} \\
\hline & $\mathbf{N}$ & $\%$ & $\mathbf{N}$ & $\%$ & $\mathbf{N}$ & $\%$ & & \\
\hline \multicolumn{9}{|l|}{$\begin{array}{l}\text { Forma de } \\
\text { comercialização }\end{array}$} \\
\hline Eviscerado & 2 & 18,2 & 5 & 20,8 & 7 & 70,0 & 14 & 31,1 \\
\hline Fresco inteiro & 6 & 54,6 & 2 & 8,3 & 3 & 30,0 & 11 & 24,4 \\
\hline As duas formas & 3 & 27,3 & 17 & 70,8 & 0 & 0,0 & 20 & 44,4 \\
\hline \multicolumn{9}{|l|}{ Higiene dos utensílios } \\
\hline Bom & 1 & 9,1 & 6 & 25,0 & 0 & 0,0 & 7 & 15,6 \\
\hline Ruim & 1 & 9,1 & 0 & 0,0 & 0 & 0,0 & 1 & 2,2 \\
\hline Péssimo & 9 & 81,8 & 18 & 75,0 & 10 & 100,0 & 37 & 82,2 \\
\hline \multicolumn{9}{|l|}{ Vestimenta } \\
\hline Bom & 2 & 18,2 & 6 & 25,0 & 7 & 70,0 & 15 & 33,3 \\
\hline Ruim & 1 & 9,1 & 0 & 0,0 & 0 & 0,0 & 1 & 2,2 \\
\hline Péssimo & 8 & 72,7 & 18 & 75,0 & 3 & 30,0 & 29 & 64,4 \\
\hline \multicolumn{9}{|l|}{ Qualidade do peixe } \\
\hline Excelente & 3 & 27,3 & 11 & 45,8 & 9 & 90,0 & 23 & 51,1 \\
\hline Bom & 2 & 18,2 & 13 & 54,2 & 1 & 10,0 & 16 & 35,6 \\
\hline Ruim & 0 & 0,0 & 0 & 0,0 & 0 & 0,0 & 0 & 0,0 \\
\hline Péssimo & 6 & 54,6 & 0 & 0,0 & 0 & 0,0 & 6 & 13,3 \\
\hline \multicolumn{9}{|l|}{ Higiene do ambiente } \\
\hline Bom & 0 & 0,0 & 7 & 29,2 & 9 & 90,0 & 16 & 35,6 \\
\hline Ruim & 0 & 0,0 & 1 & 4,2 & 0 & 0,0 & 1 & 2,2 \\
\hline Péssimo & 11 & 100,0 & 16 & 66,7 & 1 & 10,0 & 28 & 62,2 \\
\hline \multicolumn{9}{|l|}{ Destino dos resíduos } \\
\hline Prefeitura & 9 & 81,8 & 15 & 62,5 & 6 & 60,0 & 30 & 66,7 \\
\hline Alimentação animal & 2 & 18,2 & 9 & 37,5 & 4 & 40,0 & 15 & 33,3 \\
\hline \multicolumn{9}{|l|}{ Outra ocupação } \\
\hline Não & 10 & 90,9 & 21 & 87,5 & 9 & 90,0 & 40 & 88,9 \\
\hline Sim & 1 & 9,1 & 3 & 12,5 & 1 & 10,0 & 5 & 11,1 \\
\hline
\end{tabular}

Segundo OETTERER (2001), quando o peixe encontra-se no seu habitat é um produto hígido, todavia, após ser retirado da água, suas características intrínsecas favorecem o desenvolvimento microbiano devido as. Por isso, em algumas condições é mais indicado armazená-lo em gelo do que eviscerá-lo e utilizar uma água que não está dentro dos padrões de potabilidade estabelecidos pela legislação para realizar a etapa de lavagem.

Em relação às condições higienicossanitárias, foi constatado que $84,4 \%$ dos utensílios utilizados não estavam em boas condições de conservação ou eram inadequados para manipulação do peixe, como por exemplo, tábuas contendo pregos enferrujados utilizados para realizar a descamação, tábuas e facas de madeira entre outros utensílios não permitidos pela legislação vigente. No tocante às vestimentas, $66,6 \%$ não eram adequadas, ou seja, a maioria do pessoal envolvido 
no processo da comercialização não utiliza Equipamento de Proteção Individual (EPI), como luvas, botas, toucas e aventais (Tabela 1). Nas situações mais extremas, foram observados vendedores usando somente bermuda e chinelo.

Em estudo realizado na região Norte do Brasil por FREIRE et al. (2011), no estado do Pará, verificou-se que $61 \%$ do pescado comercializado no município de Bragança é realizado na feira livre, apresentando condições precárias de infraestrutura e ausência de vestimenta e equipamentos adequados.

$\mathrm{Na}$ região Nordeste, no estado da Paraíba, GOMES et al. (2012) estudaram os aspectos higiênicos da comercialização de carnes em feira livre. No quesito condições da conservação dos utensílios, eles detectaram que $66,6 \%$ dos utensílios usados para beneficiar a carne de peixe estavam em péssimas condições, corroborando com os achados do presente trabalho. Para LIMA \& SANTOS (2014), a exposição do pescado à temperatura ambiente, adotada pelos comerciantes das feiras livres, somada à ausência de cuidados sanitários contribui para perdas significativas da qualidade desse alimento.

A qualidade do peixe foi avaliada com base nos parâmetros descritos pela Instrução Normativa № 25 de 2 de junho de 2011, que descreve as características organolépticas do peixe próprio para consumo (BRASIL, 2011). No município de Matinha, $90,0 \%$ do peixe comercializado foram classificados como sendo de excelente qualidade, pois, ainda estavam vivos, ou seja, recém-capturados, portanto, em conformidade com os parâmetros de qualidade. Atribui-se esse achado aos hábitos dos consumidores dessa região de adquirem o peixe para preparo imediato, favorecendo a rápida comercialização (Tabela 1).

Foi observado que em $64,4 \%$ das barracas avaliadas nos três municípios, a higiene do ambiente não estava em boas condições, principalmente nas feiras livres de São Bento e Pinheiro, que apresentavam muitas sujidades, barracas de madeira sem proteção, presença de animais domésticos e ausência de água potável para lavagem e higienização dos utensílios. Já no município de Matinha, onde o comércio era realizado no mercado municipal, os boxes eram azulejados, o espaço fechado dificultava a entrada de animais, e havia tela na parte aérea da estrutura buscando dificultar a presença de animais voadores no local.

A falta de higiene foi observada em todos os municípios avaliados, evidenciando que a ausência de medidas sanitárias corretas, associadas com a falta de higiene dos utensílios, do ambiente e de higiene pessoal podem resultar na perda de qualidade do produto, além de perdas econômicas. CAMPOS \& PAIVA (2011),que se depararam com uma problemática semelhante na cidade de Manaus, além da conscientização como uma das ações mitigatórias, destacam a necessidade de medidas mais duras como penalizar quem contribui para as péssimas condições de higiene no ambiente.

De acordo com BARRETO et al. (2012), a falta de conhecimento quanto às Boas Práticas de Fabricação (BPF) baseadas nas normas da Agência Nacional de Vigilância Sanitária (ANVISA), podem ser apontadas como causa de inconformidades na comercialização de alimentos de origem animal. Tal fato reforça a necessidade de ações voltadas para a formação de recursos humanos para atuar na cadeia produtiva da pesca artesanal.

No que se refere aos resíduos gerados com a evisceração do peixe, verificou-se que nos três municípios pesquisados, $66,7 \%$ do quantitativo dos resíduos produzidos eram de responsabilidade da prefeitura, que realiza a coleta e os descarta em aterros comuns (lixões). Os outros $33,3 \%$ dos resíduos eram destinados, principalmente, à alimentação de animais como suínos e aves 
domésticas, o que torna evidente a necessidade de ações que incentivem o aproveitamento dos resíduos.

Além do resíduo gerado durante o processo de manipulação do peixe durante a comercialização, há um desperdício significativo de exemplares de peixes de pequeno porte, que vêm como fauna acompanhante. Segundo VIEGAS et al. (2011), a utilização das sobras dos processamentos é um procedimento importante, haja vista que, além de minimizar o impacto negativo ao meio ambiente pode gerar novos produtos, aumentando a renda do pescador.

A pesca artesanal realizada como forma de subsistência pelas famílias desses municípios ainda é uma realidade: 90,9\% dos entrevistados em São Bento, $87,5 \%$ em Pinheiro e 90,0\% em Matinha não possuem outra ocupação como fonte de renda complementar à obtida com a pesca e/ou a comercialização do peixe (Tabela 1). Realidade bem diferente foi encontrada por RAMIRES et al. (2012) em estudo desenvolvido com 174 pescadores artesanais do estado de São Paulo: a pesca não era a única atividade de sustento familiar; os mesmos buscavam complementar a renda trabalhando em várias ocupações, dentre elas, o turismo, aluguel de barcos para passeios, pesca esportiva, pousadas e restaurantes.

Desta forma, nota-se a necessidade de fomentar e incentivar o desenvolvimento das potencialidades turísticas da microrregião da Baixada Maranhense, haja vista que esta região possui a maior bacia lacustre do nordeste, com presença de campos alagados e vegetação exuberante.

\section{CONCLUSÕES}

Nos locais de comercialização do peixe, as condições higienicossanitárias e de infraestrutura são inadequadas e não há fiscalização e monitoramento do controle de qualidade, comprometendo a inocuidade desse alimento.

Sendo assim, há necessidade de campanhas educativas e orientações técnicas para as pessoas envolvidas na cadeia produtiva do peixe, pois, condições precárias desde a captura até a comercialização também contribuem para depreciação do produto, reduzindo a remuneração do pescador com a atividade pesqueira e representando riscos à saúde dos consumidores.

Fazem-se necessárias políticas públicas voltadas para a adequação da infraestrutura desses locais e para o desenvolvimento das potencialidades turísticas como atividade complementar a pesca artesanal

\section{AGRADECIMENTOS}

À Fundação de Amparo à Pesquisa e Desenvolvimento Científico do Maranhão - FAPEMA (Processo 03620/13) pelo apoio financeiro no projeto de pesquisa "Aproveitamento integral do pescado e formação de recursos humanos para atuar na cadeia produtiva da pesca artesanal em munícipios da Baixada Maranhense".

\section{REFERÊNCIAS}

BARRETO, N. S. E.; MORENO-MOURA, F. C.; TEIXEIRA, J. A.; ASSIM, D. A.; MIRANDA, P. C. Avaliação das condições higiênico-sanitárias do pescado comercializado no Município de Cruz das Almas, Bahia. Revista Caatinga, v. 25, n. 3, p. 86-95, 2012. Disponível em: < http://periodicos.ufersa.edu.br/revistas/index.php/ sistema/article/view/2209/pdf_14>. 
BRASIL. Ministério da Agricultura, Pecuária e Abastecimento. Instrução Normativa № 25, de 2 de junho de 2011. Métodos Analíticos Oficiais Físico-químicos para Controle de Pescado e seus Derivados. Diário Oficial [da] União, Brasília, DF, 03 jun 2011. Seção 1.

BRASIL. Agência Nacional de Vigilância Sanitária. Resolução de Diretoria Colegiada № 275 de 21 de outubro de 2002. Dispõe sobre o Regulamento Técnico de Procedimentos Operacionais Padronizados aplicados aos Estabelecimentos Produtores/Industrializadores de Alimentos e a Lista de Verificação das Boas Práticas de Fabricação em Estabelecimentos Produtores/Industrializadores de Alimentos. Diário Oficial [da] União, Brasília, DF, 06 nov. de 2002, Seção 1, p. 126.

BRASIL. Ministério da Pesca e Aquicultura. Potencial brasileiro. 2014. Disponível em: <http://www.mpa.gov.br/aquicultura/potencial-brasileiro>. Acesso em: 05 abr. 2016.

CAMPOS, D.S.; PAIVA, Z. C. Condição higiênico-sanitária do pescado comercializado em feira no município de Manaus - AM. Cadernos da PósGraduação da Fazu, v. 2, 2011. Disponível em: <http://www.fazu.br/ojs/index.php/ posfazu/article/viewFile/405/297>.

FAO. The state of world fisheries and aquaculture (SOFIA). Rome, 2012. 209 p.

FREIRE, J. L.; DA SILVA, B. B.; DE SOUZA, A. S. Aspectos Econômicos e Higiênico-Sanitários da Comercialização do Pescado no de Município de Bragança (PA). Revista Biota Amazônia, v. 1, n. 2, p. 17-28, 2011. Disponível em: $<$ https://periodicos.unifap.br/index.php/biota/article/viewFile/250/v1n2p17-28.pdf> doi: http://dx.doi.org/10.18561/2179-5746/biotaamazonia.v1n2p17-28.

GOMES, P. M. A.; BARBOSA, J. G.; COSTA, E. R.; S. JUNIOR, I. G. Avaliações das condições higiênicas sanitárias das carnes comercializadas na feira livre do município de Catolé do Rocha-PB. Revista Verde de Agroecologia e Desenvolvimento Sustentável, v.7, n.1, p. 225 - 232, 2012. Disponível em: <http://www.gvaa.com.br/revista/index.php/RVADS/article/view/1185/1128>.

IBGE - Instituto Brasileiro de Geografia e Estatística. Censo Demográfico. 2010. Disponível em: <http://www.ibge.gov.br/home/estatistica/populacao/censo2010/> Acesso: 20 fev. 2016.

LIMA, J. F.; SANTOS, T. S. Aspectos econômicos e higiênico-sanitários da comercialização de camarões de água doce em feiras livres de Macapá e Santana, Estado do Amapá. Revista Biota Amazônia, v. 4, n. 1 p. 1-8, 2014. Disponível em: <https://periodicos.unifap.br/index.php/biota/article/view/685/v4n1p1-8.pdf> doi: http://dx.doi.org/10.18561/2179-5746/biotaamazonia.v4n1p1-8.

MARUYAMA, L.S.; CASTRO, P.M.G.; PAIVA, P. Pesca artesanal no Médio e Baixo Tietê, São Paulo, Brasil: aspectos estruturais e socioeconômicos. Boletim do Instituto de Pesca, v. 35, n. 1, p. 61-81, 2009. Disponível em: $<\mathrm{ftp}: / / f t p . s p . g o v . b r / f t p p e s c a / 35 \_1 \_61-81 . p d f>$. 
OETTERER, M. Tecnologia do pescado. Piracicaba: Escola Superior de Agricultura "Luiz de Queiroz", 2001. Disponível em: <http://www.esalq.usp.br/departamentos/lan/pdf/Tecnologia\%20do\%20Pescado.pdf> Acesso em: 25 fev. 2016.

RAMIRES, M.; BARRELLA, W.; ESTEVES, A. M. Caracterização da pesca artesanal e o conhecimento pesqueiro local no vale do ribeira e litoral sul de São Paulo. Revista Ceciliana, v.4, n.1, p. 37-43, 2012. Disponível em: $<$ http://sites.unisanta.br/revistaceciliana/edicao_07/1-2012-37-43.pdf>.

SANTOS, M. P. N.; SEIXAS S.; AGGIO R. B. M.; HANAZAKI N.; COSTA M.; SCHIAVETTI A., DIAS J. A.; AZEITEIRO U. M. A. Pesca enquanto Atividade Humana: Pesca Artesanal e Sustentabilidade. Revista de Gestão Costeira Integrada, v.12, n.4, p. 405-427, 2012. Disponível em: $<$ http://www.aprh.pt/rgci/pdf/rgci-385_Santos.pdf>. doi:10.5894/rgci385.

VIEGAS, E. M. M.; ROSSI, F.; FERREIRA, D. G. S.; FERREIRA, R. G.S. Técnicas de Processamento de Peixes. Viçosa-MG: CPT, 2011. 256p. 